\title{
Price Cues and Customer Price Knowledge
}

January 2008

Eric T. Anderson

Kellogg School of Management

Duncan I. Simester

MIT Sloan School of Management 


\section{Price Cues and Customer Price Knowledge}

A price cue is defined as any marketing tactic used to persuade customers that prices offer good value compared to competitors' prices, past prices or future prices. In this paper, we review the academic literature that documents the effectiveness of different types of prices cues. The leading economic explanation for why price cues are effective focuses on the role of customer price knowledge and the ability of customers to evaluate whether prices offer good value. We survey the evidence supporting this theory, including a review of the literature on customer price knowledge. Finally, we document the boundaries of when price cues are effective and identify several moderating factors. 


\section{Introduction}

What is a good price to pay for a sixteen ounce package of baking soda? Is \$2,599 a good price for a 40” flat panel television? Classical economic theory assumes that customers have perfect information and can accurately answer such questions. Yet many customers who walk into Best Buy and see a 40” television priced at \$2,599 are unsure of both what price Circuit City charges, or whether Best Buy will lower the price in coming weeks. This lack of information provides an opportunity for retailers to influence consumers' price perceptions through the use of “price cues”.

We broadly define a price cue as any marketing tactic used by firms to create the perception that its current price offers good value compared to competitors' price, past prices or future prices. A common example is placing a sign at the point of purchase claiming an item is on "Sale". However, the definition is broad enough to also include more subtle techniques such as \$9 price endings, price matching guarantees, employee discount promotions and low advertised prices.

Our review of the existing academic research on price cues will focus on seven key results:

1. Many customers have poor price knowledge.

2. Price cues are effective at increasing demand.

3. Price cues are more effective (and actual price changes are less effective) when customers have poor price knowledge.

4. Price cues are most effective on newly introduced items and with newly acquired customers.

5. Price cues are less effective when used more often.

6. It is profitable for firms to place price cues on items for which prices are low.

7. Price cues may lower demand if used incorrectly

The evidence for these results is summarized in Table 1. Though not apparent from this summary, this body of research is notable for the range of product categories studied, extending from employee discount promotions for new automobiles to price-matching guarantees for supermarkets. We will begin our discussion by reviewing the literature on 
customer price knowledge. We then discuss both the effectiveness of price cues and theories that explain why consumers are so responsive to them.

Table 1 about here

\section{Price Knowledge}

There has been considerable research investigating customer price knowledge. Monroe and Lee (1999) cite over sixteen previous studies, most of which focus on measuring customers' short-term price knowledge of consumer packaged goods. In a typical study, customers are interviewed either at the point-of-purchase or in their home and asked to recall the price of a product, or alternatively, to recall the price they last paid for an item. In one of the earliest studies, Gabor and Granger (1961) conducted in-home interviews with hundreds of housewives in Nottingham, England. They found that consumers were able to provide price estimates for eight-two percent of the products in their study. Thus, eighteen percent of customers were not able to recall the price of an item. In addition, only sixty five percent of customers were able to recall a price within five percent of the actual price. These findings have been replicated in later studies, which generally reveal that only half of the customers asked can accurately recall prices (Allen, Harrell and Hutt 1976, Conover 1986, Progressive Grocer 1964, 1975). In perhaps the most frequentlycited study, Dickson and Sawyer (1990) asked supermarket shoppers to recall the price of an item shortly after they placed it into their shopping cart. Surprisingly, fewer than $50 \%$ of consumers accurately recall the price. Thus, despite the immediate recency of the purchase decision there is no improvement in the accuracy of the responses.

While price recall taps into consumers explicit memory recent research has suggested that consumers may encode and store price knowledge in implicit memory. Monroe and Lee (1999) argue that this implies a clear distinction between what consumers remember about prices versus what they know about prices. They remark that "the distinction between remembering and knowing contrasts the capacity for conscious recollection about the occurrence of facts and events versus the capacity for non-conscious retrieval of the past event, as in priming, skill learning, habit formation, and classical 
conditioning." (p. 214). This research suggests that price recall measures do not account for price information stored in consumers' implicit memory.

Building on this research, Vanhuele and Drèze (2002) argue that customers' long-term knowledge of prices is more accurately captured by measuring consumer price recognition and deal recognition. They survey 400 shoppers in a French hypermarket as they arrived at the store. Consistent with past research, they find that consumers have very poor price recall as only $21 \%$ of customers are within five percent of the actual store price. While consumers have poor price recall the authors also show that they have significantly greater price recognition. ${ }^{1}$ This support the belief that multiple measures may be required to capture all aspects of customer price knowledge.

While Vanhuele and Drèze's (2002) work provides convincing evidence that price recall and price recognition are different constructs, it also leaves several unanswered questions. For example, we do not know the determinants of price recognition or which of these determinants are different from that of price recall. Moreover, the distinction between price recall and price recognition has received only limited attention in the price cue literature. As we will discuss, the leading economic explanation for the effectiveness of price cues depends critically on lack of customer price knowledge. However, this theory does not distinguish between the inability of customers recall prices and their inability to recognize them.

We now turn to the price cue literature, starting with the early work measuring whether price cues are effective.

\section{Effectiveness of Price Cues}

Academic research has now documented that price cues can have a large positive impact on demand. For example Inman, McAlister and Hoyer (1990) simulate a grocery shopping environment and find that price cues significantly increase demand. In one of

\footnotetext{
${ }^{1}$ The authors measure aided price recognition as the ability of a consumer to tell whether an observe price is the one "they have in mind" or “are used to seeing” (see Monroe, Powell and Choudhury 1986).
} 
the first papers to employ scanner data, Guadagni and Little (1983) find that the impact of a price cue (a display or feature) is an order of magnitude greater than price. Subsequent studies of scanner data have replicated this effect and find large, positive effects of instore features and displays on consumer choice.

One challenge to empirically estimating the effect of a price cue is that price discounts often vary with price cues. Field studies have been used to isolate the impact of a price cue from a change in price. Inman and McAlister (1993) conduct a series of price experiments in a grocery store located on the campus of a major university. In nine categories they find that price cues can increase profits by $10 \%$ relative to using only price discounts. Anderson and Simester report on a number of field tests conducted with direct mail retailers in which they vary price cues. In these experiments, consumers are randomly assigned to a condition and receive different versions of a retail catalog. The catalogs are identical except for the experimental variation in prices or price cues. They repeatedly find large positive effects; for example, demand for a dress increased by $58 \%$ when a dress includes a "Sale” sign (Anderson and Simester 2001a).

Perhaps surprisingly, the evidence that sale signs are effective extends beyond consumer packaged goods to include purchases of expensive durable goods. Busse, Simester and Zettelmeyer (2007) investigate the "employee pricing" promotions offered by the three major US domestic automobile manufacturers during the summer of 2005. These promotions allowed the public to buy new cars at the same prices that employees paid. under a program of discounted prices formerly offered only to employees. While the promotions led to almost unprecedented sales increases, Busse, Simester and Zettelmeyer (2007) show that these demand increases cannot be attributed to price changes. All three manufacturers were offering deep discounts in the weeks before the promotion, and for many models the employee prices were higher than the prices immediately before the promotion. For these models prices increased under the promotion, yet even on these models demand increased dramatically under the promotion. After ruling out alternative explanations, such as a change in advertising expenditure, the authors interpret the findings as evidence that the employee discount promotion acted as price cues, 
convincing customers to purchase immediately rather than delay in anticipation of future discounts. Although there is evidence that customers engage in extensive price search when purchasing an automobile (see for example Bayus 1991; Ratchford and Srinivasan 1993; and Zettelmeyer, Scott Morton and Silva-Risso 2006) customers cannot search on “future prices," and so they must rely on price cues to evaluate when to purchase. The findings are noteworthy because they demonstrate that customers also respond to price signals in a market in which high dollar values are at stake and customers engage in extensive information search.

Practitioners in the packaged goods industry also recognize that price cues can have a significant, positive impact on demand. For example, in a 1989 interview, a manager at H.E.B. Grocery Company commented:

“Occasionally we attach signs marked "Everyday Low Price” in front of two randomly selected brands in several product categories throughout our store, leaving their prices unchanged. Even though customers should be accustomed to these signs and realize that the prices are unchanged, sales typically double for those brands that have the signs attached to their displays. I'm just amazed.” (Inman, McAlister and Hoyer 1990, at page 74)

\section{Explanations for Why Price Cues Are Effective}

Researchers have pursued different explanations for the effectiveness of price cues. Inman, McAlister and Hoyer (1990) extend the Elaboration Likelihood Model (ELM) of Petty and Cacioppo (1986) to explain the consumer response to price cues. They argue that need for cognition plays a role in whether consumers respond to peripheral information, such as a price cue. Their laboratory experiments support this theory; they find that consumers who have low need for cognition are more likely to be influenced by a price cue. $^{2}$ The work of Inman, McAlister and Hoyer (1990) is grounded in psychology

\footnotetext{
${ }^{2}$ Need for cognition (NFC) is measured using the 18-item NFC sacale developed by Cacioppo, Petty, and Kao (1984).
} 
and provides a deeper understanding of consumer behavior. However, this research does not incorporate the perspective of the firm. In particular, given that price cues are effective and seemingly inexpensive to use, why not place price cues on many items?

Anderson and Simester (1998) provide an equilibrium explanation for the role of price cues that includes both the consumer and the firm. In their model, which we depict graphically in Figure 1, if customers lack sufficient price knowledge to evaluate whether a price offers good value then demand does not response to price changes alone. Instead, customers turn to price cues to help judge value.

Figure 1 about here

The key to their model are the relationships connecting the firm decisions (depicted in the two shaded boxes) with customer decisions. These relationships ensure that retailers' price cue strategies and customers’ purchasing behavior are both endogenous and rational. There are two key predictions. First, the model shows that if customers believe that products with price cues are more likely to be relatively low priced then firms prefer to place sale signs on lower priced products. As a result, customers' beliefs are reinforced and price cues provide a credible source of information. Second, the authors show that if firms use price cues too frequently then customers will attribute less credibility to the cues and they lose their effectiveness. This in turn creates incentives for firms to limit the proliferation of the cues. These two predictions jointly imply that price cues are both self-fulfilling and self-regulating.

In 2001 the same authors (Anderson and Simester 2001a) tested the second prediction by investigating whether price cues are less effective when used more often. The findings confirm that holding price constant, overuse of sale signs can diminish their effectiveness. Support for this prediction is found in many industries, including women's apparel, toothpaste, canned tuna fish, and frozen orange juice. For example, category demand for frozen orange juice decreases when more than $30 \%$ of items have sale signs. Similarly, category demand for canned tuna fish and toothpaste decreases when more 
than $25 \%$ of the items have sale signs. Notice that this effectively limits firms' use of price cues. Adding one more price cue to an item in a category increases demand for that item, but the other price cues in the category lose their effectiveness. When this second effect is large enough, there is eventually a decrease in category demand, which regulates overuse of the cues.

A recent large-scale field study with a chain of convenience stores has also directly evaluated the first prediction (Anderson, Cho, Harlam and Simester 2007). Although we delay a detailed discussion of this study until later in the chapter, the findings both confirm that it is profitable for firms to use price cues on items that are truly low priced, and diagnose why this is optimal.

Notice also that while the equilibrium framework reconciles the consistency of customer beliefs and firm actions, it does not speak to how these beliefs are created. It is sufficient that over time customers have learned to associate price cues with low prices, and that this understanding influences their purchasing behavior. Indeed, it is possible that customers' reactions to price cues occur at a sub-conscious level, so that they are not always aware that they are responding to the cues. The formation of customer beliefs and the extent to which customer reactions reflect conscious judgments both remain important unanswered research questions.

\section{The Role of Reputations}

Reputations provide another rationale for why firms may not use price cues in a deceptive manner (Tadelis 1999; and Wernerfelt 1988). A firm’s reputation may be irreparably damaged if consumers expect that a price cue signals a promoted price and later discover that the price is not discounted. Data from two competing retailers illustrate the pitfall of using sale signs deceptively. In spring 1997, we collected data from two retailers located approximately one mile apart in Rochester, New York. The retailers sold a broad range of electronics, home appliances and other hard goods. After several visits to both stores, we identified a set of eighty five identical items sold by each retailer. We visited each 
store on the same day and collected the regular price and sale price (if discounted) for all eighty five items.

In our analysis of the data we asked: "Does the presence of a sale sign accurately convey that prices are low compared to a competing retailer?” To answer this question, we identified all cases where a product had a sale sign at one store but no sale sign at the competing store. If a sale item is truly low priced, we expect that the sale price should be less than the regular price of a competitor. More importantly, the sale price should never exceed a competing stores regular price. Our results are summarized in Figure 2.

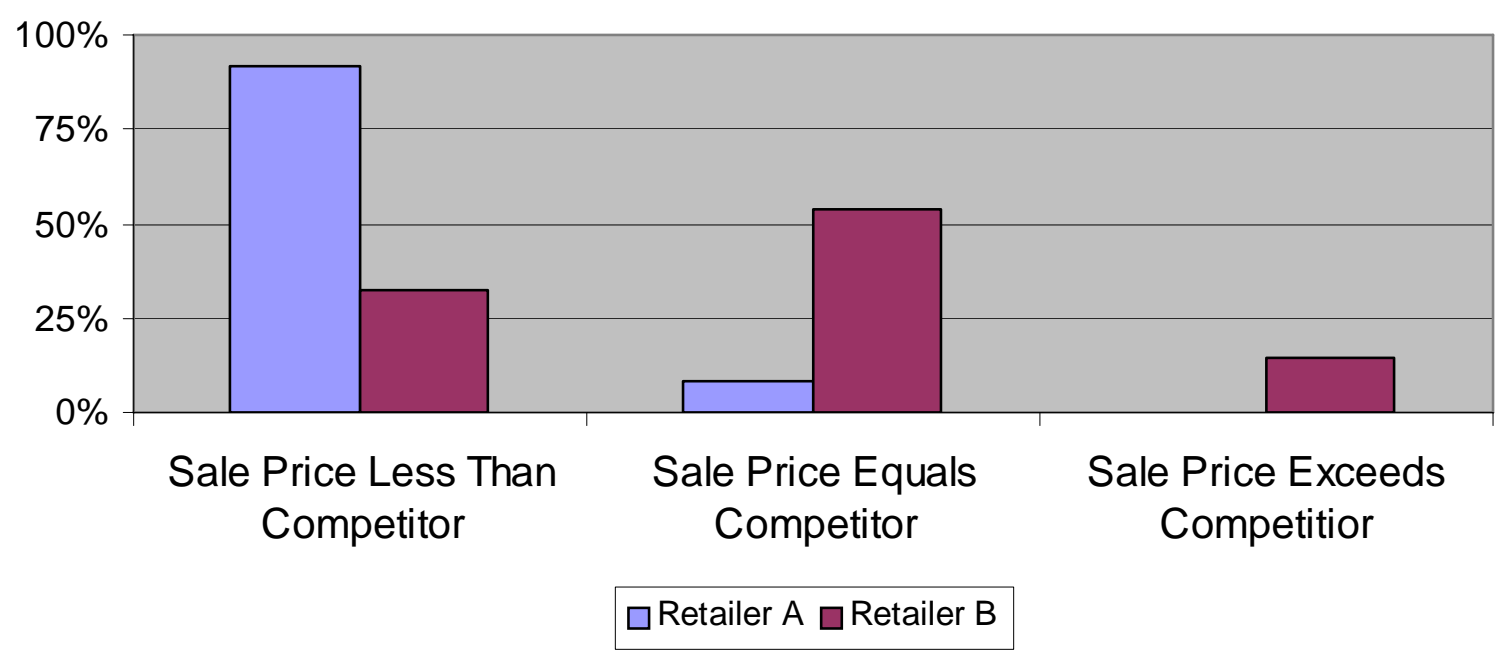

Figure 2: Accuracy of Sale Claims at Two Competing Retailers

The results showed that retailer A used sale signs to accurately signal that the current price was lower than competitors prices. We found that $92 \%$ of the items marked as "Sale" at retailer A were priced less than retailer B. For the remaining $8 \%$ of the observations the prices at both retailers were identical. In contrast, at retailer B the presence of a sale sign was not nearly as accurate and in many cases deceptive. We found that only $32 \%$ of the items marked with a sale sign at retailer B were lower priced that retailer A. More striking was the fact that $14 \%$ of the items marked with a sale sign at retailer B had sale prices that exceeded the regular price at retailer A! Thus, while the 
sale items may have been discounted relative to past prices at retailer B, they were not low priced compared to the alternative of visiting retailer A.

In both cases, the retailers were using the sale signs in a manner that is somewhat noisy. Retailer B was using the signs in a manner that was less informative and potentially misleading. Two years after this study, retailer B declared bankruptcy and went out of business. While we cannot claim a causal link between the retailer's financial distress and price cue policy, the anecdote does suggest that a firm's reputation can be damaged if price cues are used deceptively.

\section{Price Cues as Information}

The Anderson and Simester theory argues that price cues may serve an informational role when consumers have imperfect price knowledge. We consider a series of studies that support this view and illustrate other types of price cues.

\section{Price Endings}

Academics have been fascinated by the use of 9 digit price endings for over seventy years (Ginzberg 1936). This is in part due to their widespread use by U.S. retailers - while estimates vary, as many as $65 \%$ of prices have been estimated to end in the digit 9 . Despite this prevalence, there is relatively limited evidence documenting both their effectiveness and their role.

Some of the first evidence that 9 digit price endings can influence demand in retail markets is provided by Anderson and Simester (2003), who present a series of three fieldstudies in which price endings were experimentally manipulated in women's clothing catalogs. Their results confirm that in all three experiments a $\$ 9$ price ending increased demand. This prompts the question: why are 9 digit endings effective?

Several competing explanations are reviewed by Stiving and Winer (1997), including the possibility that price endings serve as a price cue. For example, Schindler (1991) suggests that price endings provide information about relative price levels and/or product 
quality. In this theory, customers pay more attention to the right-most digits because of the information that they convey. This contrasts with the customer's emphasis on the left-most digits in the “dropping off” theories. Under those alternative theories, customers ignore the right hand digits or place less emphasis on them.

There is both systematic and anecdotal evidence to support the view that price endings convey low prices. For example, Salmon and Ortmeyer (1993) describe a department store that uses a 0-cent ending for regularly priced items and 98-cent endings for clearance items. Similarly, Randall's Department Store uses 95-cent endings on all "value" priced merchandise, which is "meant to indicate exceptional value to the customer” (Salmon and Ortmeyer 1992).

These anecdotes are supported by more systematic academic studies. Schindler and Warren (1988) show that one inference customers may draw from \$9-endings is that a price is low, discounted, or on "Sale.” More recently, Schindler (2006) analyzed prices for hundreds of different products that were advertised in several newspapers. Schindler shows that items priced with a 99 cent price ending are more likely to be in an advertisement that emphasizes price discounts. ${ }^{3}$ He argues that this offers a plausible explanation for how consumers form associations between low prices and 9 digit price endings.

Anderson and Simester (2003) provide further support for the theory that 9 digit prices convey information. They show that the increase in demand from a 9 digit item is greatest for new items that a retailer has not sold in previous years. Because customers have poor price knowledge for these items, this is precisely where price cues should be more effective. The authors also show that \$9 price endings are less effective when retailers use "Sale" cues. This is precisely what we would expect if the "Sale" sign has already informed customers about whether an item is low priced.

\footnotetext{
${ }^{3}$ Schindler refers to these as low-price cues. We do not use this phrase to avoid confusion with our definition of a price cue.
} 


\section{Price Promotions for New Customers}

New customers are typically least informed about prices, and so for these customers deep promotional discounts may act as a price cue and influence their overall price perceptions for a retailer. Bagwell (1987) presents an equilibrium model of initial prices as a cue that signals information about future prices.

There is also field research investigating this possibility (Anderson and Simester 2004). The research includes three separate field experiments with a direct mail retailer that sells publishing products (books, software etc.). Study A was conducted using 56,000 existing customers. Studies B and C were conducted using 300,000 and 245,000 prospective customers identified from a rented mailing list. Each study used Promotion and Control versions of a Test Catalog sent to randomly assigned groups of customers. Prices in the Promotion condition were $40 \%$ lower than in the Control condition. The Test Catalog was otherwise identical and all of the customers received the same catalogs over the subsequent two-years.

The results show that deep promotions have different long-run impacts on the behavior of new and established customers. The established customers in Study A reacted in the same manner as documented in other studies (see for example Neslin and Shoemaker 1989). For these customers the short-run lift in demand was offset by a long-run decrease in demand, which almost certainly reflects the effects of inter-temporal demand substitution (forward-buying). In contrast, the deep promotions had a positive long-run impact on the demand of new customers (Studies B and C). Receiving deep discounts on their first purchase occasion prompted these customers to return and purchase $10 \%$ to $21 \%$ more frequently in the future. Further investigation suggests that the deep promotional discounts influenced the new customers' price perceptions. In this sense, the low initial prices served as a price cue about the overall level of prices.

\section{Signpost Items}

Consider the purchase of a new tennis racket. The models change frequently and so most customers will be unsure how much a selected model should cost. On the other hand, 
most tennis players have good price knowledge of tennis balls. If they see a store charging \$2 for a can of tennis balls they may be reassured that they are not over-paying for the tennis racket. However, if the tennis balls are \$5 a can, they may be better served purchasing their tennis racket elsewhere. Tennis balls are an example of a "Signpost" item for which many customers have good price knowledge. The price of a signpost item signals information about the prices of items for which price knowledge is poor. Other examples include customers using the prices of bread, milk or Coke, to infer whether a supermarket offers good value on baking soda.

Simester (1995) presents an equilibrium model of the signaling role of signpost items. In his model, customers see the prices of a sample of "advertised" items and use these prices to infer the price of the "unadvertised" items for which prices are unobserved prior to visiting a store. The underlying signaling mechanism relies on correlation in the underlying costs (to the firm) of the different items. This can be compared with Bagwell's (1987) model of low initial prices, where the information revealed by a price cue depends upon correlation in the firm's costs over time. Simester tests his model using a sample of data from the Boston dry-cleaning market. He shows that the price to launder a men's shirt provides credible information about the cost to dry-clean suits and sweaters.

\section{Price Guarantees}

A common strategy among retailers is to offer consumers a price guarantee. There are two widely used versions: price matching policies and best price policies. A price matching policy guarantees that prices will be no higher than the prices charged by other retailers. A typical price matching policy guarantees the consumer a rebate equal to the price (and perhaps more) if the consumer finds the same product offered at lower price by a competing firm within 30 days of purchase. Some firms, such as Tweeter, take the additional step of monitoring competitive prices for the consumer and sending the consumer a rebate automatically. While price matching policies protect the consumer against price differences among competing retailers, best price policies protect consumers against future discounts within a retail store. For example, when a retailer discounts an 
item by $25 \%$ a best price policy promises to refund this discount to all consumers who purchased the item in the previous 30 days.

Both types of price guarantees are intended to create the perception that an item is low priced compared to competing retailers (price matching policy) or the firm's future prices (best price policy). Studies measuring the relationship between price guarantees and consumer price perceptions confirm that they can be an effective price cue, leading to more favorable price perceptions (see for example Jain and Srivastava 2000).

There is also evidence that price guarantees can affect price levels themselves, by influencing the intensity of competition. One stream of theoretical research suggested that these price guarantees may serve as a mechanism that raises market prices (Salop 1986). Another stream suggested that these policies may increase competition in a market (Chen, Narasimhan and Zhang 2001). These two streams of research show that whether price matching policies lead to increased competition hinges on the degree of heterogeneity in consumer demand. This research has also highlighted subtle distinctions between price matching, price beating, and best price policies. The empirical evidence is also mixed. Hess and Gerstner (1991) show that supermarkets that offer price matching policies have less price dispersion and higher prices. In contrast, there is evidence that retailers who adopt price matching policies reduce their prices. For example, when Montgomery Ward and Tops Appliance City introduced such policies they significantly lowered their prices (PR Newswire 1989, Beatty 1995, Halverson 1995, Veilleux 1996).

\section{The Moderating Role of Price Knowledge}

The Anderson and Simester model predicts that price cues are most effective when consumers lack price knowledge. If consumers know that $\$ 4$ is a relatively high price for a gallon of milk, then adding a price cue should have little impact on demand. But, if customers are uncertain about the relative price of milk a price cue may affect purchase behavior. In a recent paper, Anderson, Cho, Harlam and Simester (2007) combine survey data and a field experiment to investigate this prediction. In their study, they survey 
customers and collect price recall measures for approximately two hundred products. They then conduct a field experiment in which they randomly assign the same items to one of three conditions. In the control condition, items are offered at the regular retail price. In the price cue condition, a shelf tag with the words "LOW prices" is used on an item. In the discount condition, the price is offered at a $12 \%$ discount from the regular price.

The authors show that both price cues and price discounts increase demand. But, consistent with theoretical predictions, the authors find that price cues are more effective on products for which customers have poor price knowledge. In contrast, price discounts are more effective when customers have better price knowledge. Thus, discounting baking soda from 99 cents to 89 cents is unlikely to be effective since customers have poor price knowledge for this product. But, an offer of “Sale 99 cents” may lead to a large increase in demand. Together these results highlight the importance that price knowledge serves in determining the effectiveness of price changes and price cues.

\section{Adverse Effects of Price Cues}

While price cues are intended to increase demand, retailers must recognize that they can also have an adverse impact on demand. Below we document three situations where a price cue reduced demand.

\section{Regular Price}

When an item is offered at a discount many customers are unable to recall the previous price. Including the regular price allows consumers to directly assess whether an item is low priced compared to past prices. One might be tempted to conclude that providing customers with this price cue would be beneficial, but a recent study we conducted with a direct mail company explains why this may not be correct. In this study, we varied the presence or absence of the regular price on a set of five dresses. For example, the regular price of one dress was $\$ 120$ and it was discounted to $\$ 96$. Customers who received the control catalog saw this dress offered at “Sale \$96.” Customers who received the test catalog saw “Regular Price \$120, Sale \$96.” 
The results of this study showed that demand significantly decreased when the regular price was included in the description. The presence of this price cue resolved customer uncertainty about the depth of discount. But, the resolution of this uncertainty was unfavorable. In the absence of the regular price, customers expected to receive more than a \$24 discount. Thus, while price cues can help resolve customer uncertainty firms must also ask whether it is profitable to resolve the uncertainty. In some case, customers may have more favorable price perceptions when they lack perfect information.

\section{Installment Billing}

If customers lack perfect information about prices they may also have imperfect knowledge of quality. Price cues are intended to create the perception of a low price and increase demand. But, if the price cue also creates the perception of low quality then demand may decrease. For example, Fingerhut is a catalog retailer in the United States that offers installment billing on nearly all purchases. While Fingerhut also offers low priced merchandise they target consumers with moderate to low incomes. This raises the possibility that consumers may believe that Fingerhut is positioned to offer both lower priced and lower quality items. If the quality inference dominates, then offering installment billing may adversely impact demand.

Anderson and Simester (2001b) document such an effect in a field experiment with a national mail order company. The research was conducted with a catalog that sells expensive gift and jewelry items and competes with retailers such as Tiffany's. In the experiment, customers were randomly mailed either a test or control catalog. The products and prices were identical except that the test catalog offered consumers the option of paying for their purchase with installment billing. For example, if a customer purchased a \$500 necklace, the item could be paid for with a series of monthly payments

rather than in a single lump sum payment. Installment billing was an optional feature and consumers who received the test catalog were free to select either payment plan (i.e, installment billing or lump sum payment). 
The authors show that installment billing offer led to both a reduction in the number of orders received (13\%) and a \$15,000 reduction in aggregate revenue (5\%). The sample sizes are very large and so the differences in the number of orders received between the Test and Control Version are statistically significant $(\mathrm{p}<0.01)$. The changes were economically significant and convinced catalog managers to not include installment billing offers in future catalogs.

To further investigate these findings, the catalog agreed to survey their customers to measure how an offer of installment billing affects their customers' price and quality perceptions. Similar to the field test, two versions of a catalog were created and customers were randomly mailed a catalog along with a short survey. Respondents were asked to browse through the catalog and return their responses in a reply paid envelope. The findings confirm that offering installment billing lowers the perceived quality of the items in the catalog. Respondents in the Test Version were on average significantly more concerned about product quality than respondents in the Control Version. One respondent in the Test Version offered the following remarks: "My reaction to this catalog is that people must be cutting back or not as rich as [the catalog] thought because suddenly everything is installment plan. It makes [the catalog] look tacky to have installment plans - kind of like Franklin Mint dolls.”

These findings contrast with earlier work suggesting that reframing a one-time expense into several smaller expenses can favorably impact demand (see for example Gourville 1998). The key distinction is the role of quality. In the installment billing study product quality was not objectively verifiable, and so the installment billing cue not only influenced customers' price perceptions, it also lowered their quality perceptions. The same logic may explain why hospitals rarely use price cues to persuade customers that their prices are low.

\section{Prices Paid by Other Consumers}

We have argued that price cues can convey information about competing prices, past prices or future pries. However, research on fairness suggests that whether consumers 
view a price as a good deal or a bad deal may also depend on what other consumers pay for similar products. Anderson and Simester (2007a) conduct a field experiment with direct mail apparel to investigate this issue. They conducted a split-sample test in which they experimentally varied the price premium on larger sized women's dresses. In the control condition the prices of dresses did not vary by size. But, in three test conditions a premium of up to $\$ 10$ was charged for larger sized $4 \mathrm{X}$ and $5 \mathrm{X}$ dresses. For example, a size 3X dress may be priced at $\$ 39$ and a $4 \mathrm{X}$ dress priced at $\$ 44$. The experimental variation in prices enables the authors to examine how the price paid by other consumers affects demand.

The key finding is that customers who demand large sizes react unfavorably to paying a higher price than customers for small sizes. Further investigation suggests that these consumers perceived that the price premium was unfair. This finding is consistent with other evidence from the fairness literature, which contains many documented examples of customers reacting adversely when they perceive that prices are unfair (see for example Xia, Monroe and Cox 2004; and Anderson and Simester 2007b)

\section{Managing Price Cues}

If price cues are effective then how should managers use them? The research we have reviewed in this chapter suggests that price cues are more effective among customers who lack price knowledge. Because we expect price knowledge to vary among products, a natural response is to use price cues on products for which customers have poor price knowledge. Similarly, price discounts are more effective when customers have better price knowledge. This creates an incentive to discount items for which customers have good price knowledge. Anderson, Cho, Harlam and Simester (2007) discuss why this presents a puzzle. For example, consider two items priced at $\$ 4$ that differ in price knowledge. Suppose a firm lowers the price on an item with high price knowledge and uses a price cue on the other item. If firms pursue this strategy, then rational customers will infer that price cues are associated with products that are relatively high priced! 
To address this issue, Anderson, Cho, Harlam and Simester (2007) identify three factors that moderate use of price discounts and price cues: total demand, margin and demand sensitivity. Holding all other factors constant, it is less profitable to use a price discount on a high demand item due to the opportunity cost of a price reduction. Both price discounts and price cues are more profitable on high margin items and on products with greater demand sensitivity. The question for managers is which of these three factors is most important?

To answer this question, the same authors conduct a large scale field test with a convenience store chain in which they vary price discounts and price cues on almost two hundred items. The authors analyzed which factors best explain the change in profits when a firm uses a price discount or a price cue. The results show that demand sensitivity is the overwhelming factor that drives incremental profits earned from both price cues and price discounts. Moreover, the sensitivity of demand is positively correlated across both treatments, so that items for which there is a greater price response, are also items for which there is a great response to price cues. This finding is important for both managerial practice and the academic theories we have discussed in this chapter. It implies that price cues and price discounts are likely to be used on the same items, and may help to resolve the apparent puzzle, explaining why price cues provide a credible signal of low prices.

A related concern of managers is how to use price cues in a competitive setting. Can price cues be an effective competitive tool? A recent study conducted with a German direct marketer of books examines precisely this question (Anderson, Elsner, Rossi and Simester 2007). The company owns three different catalog companies that sell primarily books and music CDs. While the companies each have a distinct brand name they are owned by a single firm. Importantly, from the consumer's perspective the three brands are viewed as competing retailers. This allows the parent company to study how price cues and price changes affect retail book competition. 
The retailer conducted a field study in which they varied both prices and price cues on a set of twenty nine products sold by three different book retailers. The findings reveal that price cues lead to substitution between catalogs, confirming that they can be an effective competitive tool.

The study also showed that customer groups reacted quite differently to price cues and price changes. The company found that price cues were effective at increasing demand among moderate book buyers, but the demand increase did not come at the expense of competing catalogs. Instead, the increased demand from a price cue was incremental. In contrast, among heavy book buyers there was considerable evidence that price cues led to store substitution. This understanding of consumer behavior offers deeper insight into the competitive nature of price cues. Surprisingly, the threat of a competing price cue is greatest among customers who are the heaviest buyers in a category.

\section{Managing Price Knowledge}

Because the effectiveness of price cues is moderated by customers' price knowledge, firms may also try to manage their customers’ price knowledge. Indeed, the recent literature on price obfuscation suggests that customers' lack of price information may be partly attributable to the actions of the firms. The role that firms can play in hindering customers' ability to search for price information is investigated by Ellison and Ellison (2004). They argue that price obfuscation can mitigate price competition by reducing the perceived substitutability of the alternatives, and present evidence from the Internet suggesting that obfuscation may sharply increase margins on computer memory modules. They describe a variety of practices that firms use to obfuscate the price, including: introducing shipping costs and other price components; varying warranties, re-stocking fees and other contractual terms; varying prices and products across distribution channels; and/or using "add-on” pricing in which the base product has inefficiently low quality.

\section{Conclusions}


The research on price knowledge reveals that there is an opportunity for firms to influence customers' price perceptions, while the research on price cues documents examples of firms exploiting this opportunity. There are several important conclusions. First, the range of cues available to firms is broad, ranging from explicit claims that prices are discounted to more subtle cues, such as 9-digit price endings, which may work even without customers recognizing their effect. Second, the cues are effective across many product categories. We have reported findings from studies conducted in wide range of consumer markets, including consumables (toothpaste, caned tuna and frozen juice) and durables (apparel and publishing products). There is even evidence that the cues are effective in the market for new automobiles, where the prices are high and customers engage in extensive price search. Third, there is now a formidable collection of evidence that at least one reason price cues are effective is that they serve a signaling role, allowing customers who are poorly informed about prices to infer whether to search elsewhere for lower prices. This evidence includes investigations of several moderating effects, including: the role of customers' price knowledge, the effects on new versus mature products, and the effect on newly acquired versus established customers. Finally, there is evidence that price cues are not a magic panacea that firms can employ at will. The cues lose effectiveness the more often they are used, and so firms cannot simply place them on every product. Firms also risk lowering demand if they place them on items for which quality is uncertain (few patients are attracted to a cardiologist offering discounts) or if customers can see that other customers have the opportunity to purchase similar items at lower prices. On the other hand, firms that overlook the role of price cues, and focus solely on optimizing prices, forgo an opportunity to optimize profits. 


\section{References}

Allen, J. W., G. D. Harrell, and M. D. Hutt (1976), Price Awareness Study, The Food Marketing Institute, Washington D.C.

Anderson, Eric T., Edward Ku Cho, Bari Harlam and Duncan I. Simester (2007), "Using Price Cues,” mimeo, MIT, Cambridge MA.

Anderson, Eric T., Ralph Elsner, Federico Rossi and Duncan Simester (2007), "Sale Signs and Retail Competition”, Kellogg School of Management, working paper.

Anderson, Eric T. and Duncan I. Simester (1998), “The Role Of Sale Signs” Marketing Science, Vol. 17(2), 139-155.

Anderson, Eric T. and Duncan I. Simester (2001a), “Are Sale Signs Less Effective When More Products Have Them?” Marketing Science, 20(2), 121-142.

Anderson, Eric T. and Duncan I. Simester (2001b), "Research Note: Price Discrimination as a Signal: Why an Offer to Spread Payments May Hurt Demand," Marketing Science, 20(3), 315-327.

Anderson, Eric T. and Duncan I. Simester (2003), "Effects of \$9 Price Endings on Retail Sales: Evidence from Field Experiments,” Quantitative Marketing and Economics, 1(1), 93-110.

Anderson, Eric T. and Duncan I. Simester (2003), "Mind Your Pricing Cues” Harvard Business Review, 81(9), September, 96-103.

Anderson, Eric T. and Duncan I. Simester (2004), "Long Run Effects of Promotion Depth on New Versus Established Customers: Three Field Studies,” Marketing Science, 23(1), 4-20.

Anderson, Eric T. and Duncan I. Simester (2007a), "Does Demand Fall When Customers Perceive That Prices Are Unfair: The Case of Premium Pricing for Large Sizes," Marketing Science, forthcoming.

Anderson, Eric T. and Duncan I. Simester (2007b), “Customer Antagonism and Price Stickiness,” mimeo, MIT, Cambridge MA.

Bagwell, Kyle (1987), "Introductory Price as a Signal of Cost in a Model of Repeat Business,” The Review of Economic Studies, Vol. 54(3), pp. 365-384. 
Bayus, Barry L. (1991), “The Consumer Durable Replacement Buyer,” Journal of Marketing, 55, January, 42-51.

Beatty, Gerry. 1995. “Tops' ads hail new price policy.” HFN The Weekly Newspaper for the Home Furnishing Netulork 69 (39) (September 25), 63-65.

Busse, Meghan R., Duncan Simester and Florian Zettelmeyer (2007), “The Best Price You'll Ever Get: The 2005 Employee Discount Pricing Promotions in the U.S. Automobile Industry," mimeo, MIT, Cambridge MA.

Cacioppo, John T, Richard E. Petty and Chuan F. Kao (1984), "The Efficient Assessment of Need for Cognition,” Journal of Personality Assessment, Vol. 48 (June), 306-307.

Chen, Yuxin, Chakravarthi Narasimhan; Z. John Zhang, "Consumer Heterogeneity and Competitive Price-Matching Guarantees." Marketing Science, Vol. 20, No. 3. (Summer, 2001), pp. 300-314.

Conover, Jerry (1986), "The Accuracy of Price Knowledge: Issues in Research Methodology,” in Advances in Consumer Research, Richard Lutz, ed., Vol 13. Association for Consumer Research, Ann Arbor, MI, 589-593.

Cooke, Alan D. J., Tom Meyvis and Alan Schwartz (2001), “Avoiding Future Regret in Purchase Timing Decisions,” Journal of Consumer Research, 27, March, 447-59.

Davis, Scott, Scott Davis; J. Jeffrey Inman; Leigh McAslister (1992), "Promotion Has a Negative Effect on Brand Evaluations: Or Does It? Additional Disconfirming Evidence," Journal of Marketing Research, Vol. 29, No. 1. (Feb.), pp. 143-148.

Dickson, Peter R. and Alan G. Sawyer (1990), "The Price Knowledge and Search of Supermarket Shoppers,” Journal of Marketing, 54, (July), 42-53.

Ellison, Glenn and Sara Fisher Ellison (2004), "Search, Obfuscation, and Price Elasticities on the Internet," mimeo, MIT.

Feinberg, Fred M., Aradhna Krishna and Z. John Zhang (2002), "Do We Care What Others Get? A Behaviorist Approach to Targeted Promotions,” Journal of Marketing Research, XXXIX, August, 277-291.

Gabor, Andre and Granger, C.W.J. (1961), "On the Price Consciousness of Consumers," Applied Statistics, Vol. 10, No. 3. (November), 170-188.

Ginzberg, Eli (1936), “Customary Prices,” The American Economic Review, Vol. 26(2), p. 296. 
Gourville, John T. (1998) "Pennies-a-Day: The Effect of Temporal Reframing on Transaction Evaluation,” Journal of Consumer Research, Vol. 24, No. 4, 395-408

Guadagni, Peter M. and John D.C. Little (1983), "A Logit Model of Brand Choice Calibrated on Scanner Data,” Marketing Science, Vol. 1, No. 2, Spring, p. 203-38.

Halverson, Richard. 1995. “Tops touts subdued attitude,” Discount Store News 34 (20) (16 October), 8-9.

Hess, James D. and Eitan Gerstner (1991), "Price-Matching Policies: An Empirical Case,” Managerial and Decision Economics, Vol. 12, No. 4. (Aug., 1991), pp. 305-315.

Inman, Jeffrey J. and Leigh McAlister (1993), “A Retailer Promotion Policy Model Considering Promotion Signal Sensitivity,” Marketing Science, Vol. 12, 4, 339-356.

Inman, Jeffrey J., Leigh McAlister, and Wayne D. Hoyer (1990), "Promotion Signal: Proxy for a Price Cut,” Journal of Consumer Research, Vol. 17, June, 74-81.

Jain, Sanjay and Joydeep Srivastava (2000), "An empirical and theoretical analysis of price-matching refund policies,” Journal of Marketing Research Vol. 37 (2000) (August), 351-362.

Kalyanaram, Gurumurthy and Russell S. Winer (1995), "Empirical Generalizations from Reference Price and Asymmetric Price Response Research," special issue of Marketing Science on empirical generalizations in marketing, 14 (part 2 of 2 in issue \#3), G161G169.

Monroe, Kent B. and Angela Y. Lee (1999), "Remembering versus Knowing: Issues in Buyers' Processing of Price Information," Journal of the Academy of Marketing Science, Vol. 27, No. 2, pp. 207-225.

Monroe, Kent B., Christine P. Powell, and Pravat K. Choudhury. (1986). "The Influence of Price Awareness on Price Perceptions." In R. Lutz (ed.)Advances in Consumer Research, Vol. 13. Provo, UT: Association for Consumer Research, 595-599.

Neslin, ScottA. And Robert W. Shoemaker (1989), "An Alternative Explanation for Lower Repeat Rates after Promotion Purchases,” Journal of Marketing Research, Vol. 26, No. 2. (May), 205-213.

Petty, Richard E. and John T. Cacioppo (1986), Communication and Persuasion: Central and Peripheral Routes to Attitude Change, New York: Springer-Verlag. 
PR Newswire (1989), "Montgomery Ward Reduces Prices on All Brand Name Merchandise," 17 February.

Progressive Grocer (1964), "How much do consumers know about retail prices?” (February) 104-6.

Progressive Grocer (1975), “Then and Now: Shopping Behavior 10 years apart,” (October) 37-41.

Ratchford, Brian T. and Narasimhan Srinivasan (1993), “An Empirical Investigation of Returns to Search,” Marketing Science, 12(1), 73-87.

Salmon, Walter J. and Gwendolyn K. Ortmeyer (1992), Randall's Department Stores, Harvard Business School Publishing, 9-593-032, p. 1-24.

Salmon, Walter J. and Gwendolyn K. Ortmeyer (1993), Duncan Department Stores, Harvard Business School Publishing, 9-594-012, p. 1-36.

Salop, S. (1986) "Practices that (credibly) facilitate oligopoly coordination,” in J. Stiglitz, F. Mathewson, eds. New Developmts in the Analysis of Market Structure. MIT Press, Cambridge, MA.

Schindler, Robert M. (1991), "Symbolic Meanings of a Price Ending,” Advances in Consumer Research, Vol. 18, p. 794-801

Schindler, Robert M. and Lori S. Warren (1988), “Effect of Odd Pricing on Choice of Items from a Menu,” Advances in Consumer Research, Vol. 15, p. 348-353.

Schindler, Robert M. (2006), “The 99-Price Ending as a Signal of a Low-Price Appeal,” Journal of Retailing, 82 (1), 71-77.

Simester, Duncan I. (1995), "Signaling Price Image Using Advertised Prices," Marketing Science, 14(2), 166-188.

Stiving, Mark and Russel S. Winer (1997). “An Empirical Analysis of Price Endings with Scanner Data,” Journal of Customer Research, June, 57-67.

Tadelis, Steven (1999), “What's in a Name? Reputation as a Tradeable Asset,” The American Economic Review, 89(3), 548-563.

Vanhuele, Marc and Xavier Drèze (2002), "Measuring the Price Knowledge Shoppers Bring to the Store,” Journal of Marketing, Vol. 66, (October), 72-85. 
Veilleux, C. T. 1996. “Tops loses VP, plans cutbacks,” HFN The Weekly Newspaper for the Home Furnishing Network, 70 (24) (June 10),67-68.

Wernerfelt, Birger (1988), "Umbrella Branding as a Signal of New Product Quality: An Example of Signalling by Posting a Bond,” Rand Journal of Economics, 19(3), 458-66.

Xia, Lan, Kent B. Monroe and Jennifer L. Cox (2004), "The Price is Unfair! A Conceptual Framework of Price Fairness Perceptions," Journal of Marketing. Vol. 68, 115.

Zettelmeyer, Florian, Fiona Scott Morton and Jorge Silva-Risso (2006), "How the Internet Lowers Prices: Evidence from Matched Survey and Automobile Transaction Data," Journal of Marketing Research, XLIII, May, 168-81. 


\section{Table 1. Key Research Findings}

\section{Many customers have poor price knowledge.}

See Monroe and Lee (1999) for a review of 16 studies. Subsequent research includes Vanhuele and Drèze (2002).

\section{Price cues are effective at increasing demand.}

"Sale" or "Low Price" merchandising claims: Guadagni and Little (1983); Inman McAlister and Hoyer (1990); Inman and McAlister (1993); Davis, Inman and McAlister (1992); Anderson and Simester (1998 and 2001a); Anderson, Cho Harlam and Simester (2007).

Employee discount promotions: Busse, Simester and Zettelmeyer (2001) who study the impact of the 2005 employee discount promotions in the automobile industry.

Price matching guarantees: Jain and Srivastava (2000) who present evidence that price matching claims lead to favorable price perceptions.

9-digit price endings: Schindler and Warren (1988); Schindler (1991); Salmon and Ortmeyer (1992); Stiving and Winer (1997); Anderson and Simester (2003); and Schindler (2006).

Initial prices: Bagwell (1987) presents an equilibrium model, while Anderson and Simester (2004) who compare the long-run impact of offering deep discounts to existing and newly acquired customers.

Prices of "signpost items" (for which customers have good price knowledge): Simester (1995) presents both an equilibrium model and data from the Boston dry-cleaning market.

Prices of related items: Anderson and Simester (2007a and 2007b). See also Xia, Monroe and Cox's (2004) review of the extensive literature on price fairness and Kalyanaram and Winer's (1995) review of the reference price literature.

\section{Price cues are more effective and actual price changes are less effective when customers have poor price knowledge.}

Anderson and Simester (1998) present a theoretical model, while Anderson, Cho, Harlam and Simester (2007) present empirical evidence from a chain of convenience stores.

4. Price cues are most effective on newly introduced items and with newly acquired customers.

Anderson and Simester (2003) show that 9-digit price endings are most effective on new items, while Anderson and Simester (2004) present evidence that low initial prices are most effective on new customers.

\section{Price cues are less effective when used more often.}

This is a central prediction in the Anderson and Simester (1998) model, and is tested empirically in Anderson and Simester (2001a) using data from a variety of sources.

\section{It is profitable for firms to place price cues on items for which prices are low.}

This is also a central prediction in the Anderson and Simester (1998) model. For a recent empirical investigation of this issue see Anderson, Cho, Harlam and Simester (2007).

\section{Price cues may lower demand if used incorrectly.}

Including the regular price (when customers expect a larger discount): see the results cited in this chapter.

When quality is uncertain: Anderson and Simester (2001b) show that installment billing offers can lower demand.

When prices of related items reveal that other customers pay lower prices: see Anderson and Simester (2007a and 2007b) and Xia, Monroe and Cox's (2004) review. 
Figure 1. The Equilibrium Theory of Price Cues

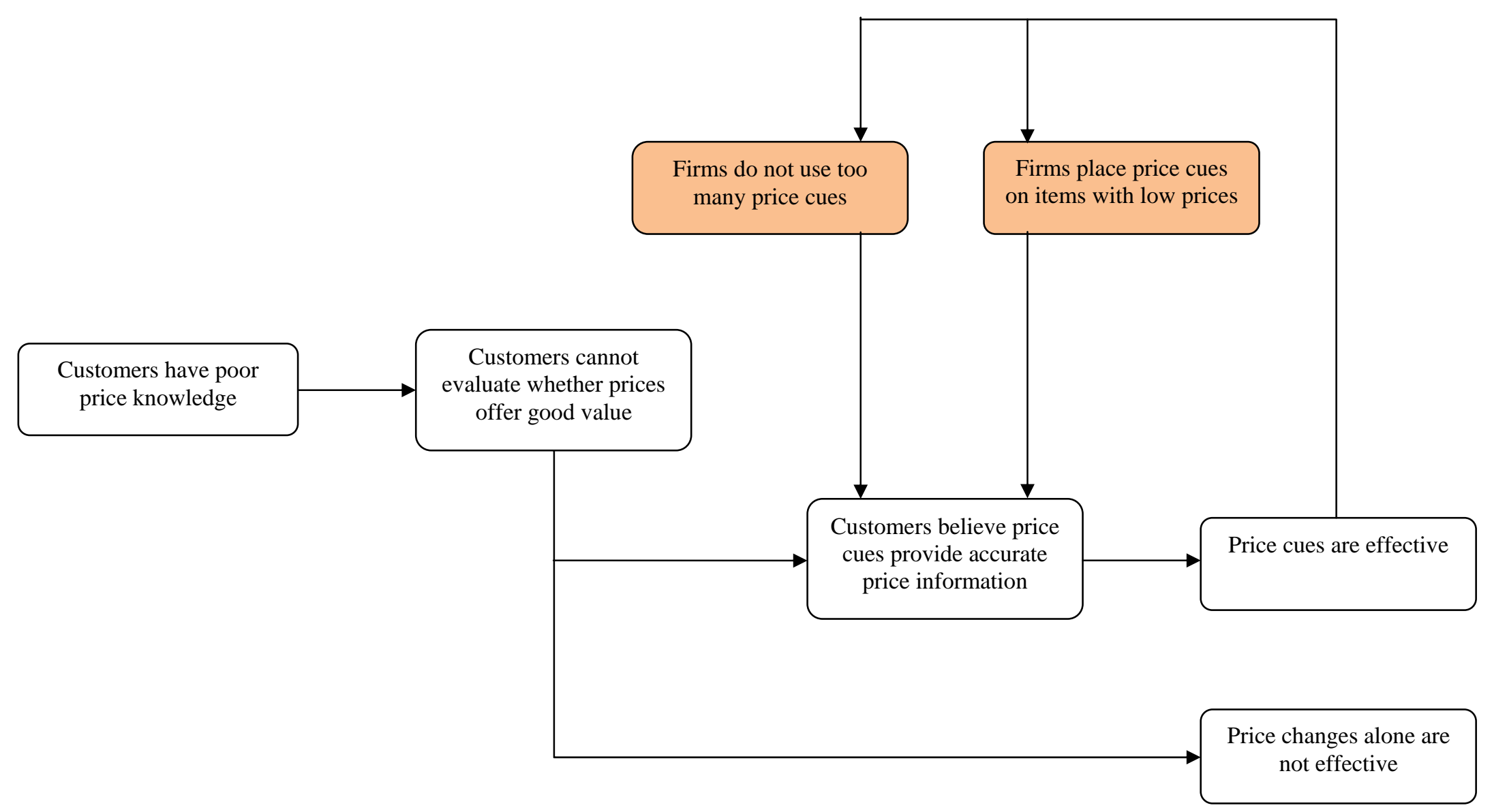

